\title{
PRODUCTIVE AND ENERGY CONSUMPTION IMPROVEMENT WITH THE USE OF A LINEAR INDUCTION MOTOR IN CEREAL DRYING MECHANICS.
}

\author{
Sussumu C. Tanimoto ${ }^{1}$, Décio Bispo ${ }^{2 *}$, J.R. Camacho ${ }^{3 *}$ \\ ${ }^{1}$ Armazéns Gerais Bom Jesus Ltda, Bom Jesus-GO, Brazil, e.mail: manutenção@bagel.com.br \\ ${ }^{2}$ Electric Machines Laboratory e.mail: bispo@ufu.br \\ ${ }^{3}$ Rural Electricity and Alternative Energy Sources Laboratory, e.mail: jrcamacho@ufu.br \\ ${ }^{*}$ School of Electrical Engineering, Universidade Federal de Uberlândia, MG, Brazil
}

\begin{abstract}
The proposed work presents a research on the efficiency of a LIM - Linear Induction Motor $[2][4][5][6][7]$, applied in a cereal drier discharge system, in order to substitute the conventional pneumatic piston system (conventional system). The work is based in the conventional system fault reduction concept, with a search for a robust and simple system, which also presents improved efficiency, low energy consumption showing technological innovation to the agricultural industry. A suitable simulator was assembled for the dryer discharge system and LIM. Operational tests were made, with the measurement of force and energy consumption. Finite Element Methods were used for comparative simulation and prototype force determination. The obtained results are very close to expected and are perfectly in agreement with the proposed final task.
\end{abstract}

Keywords- cereal drier, efficiency, linear induction motor, mechanical discharge.

\section{INTRODUCTION}

The main purpose is to improve the productive performance of cereal dryers, with reduction in losses and operational costs in the cereal reception routine. Research with application of linear induction machines in a cereal dryer discharge system revealed to be a good option for the substitution of conventional systems currently in operation extensively around the country.

This investigation makes the analysis on the cost of equipment stopping in the cereal drying flow process, with a survey of the main causes for process halting and its contribution in the results that were obtained at a warehouse in a company that works in the field of cereal drying and storage at Goiás State in Brazil.

Due to the high number of corrective interventions causing interruptions in the production flow, a research was made on the improvement of a cereal dryer discharge system, while restructuring the process flow and operating procedures due to changes in the mechanical and electrical systems. It was developed an alternative system, through the use of a LIM, that when compared with the current existing system, showed excellent results under test and simulations. This research brings significant contribution to the decreasing of global costs, with the reduction of losses referred to not receiving the product, due to frequent flux

Manuscript submitted on May 13, 2008; first revision on August 22, 2008; second revision on March 6, 2009. Recommended by the Editors of the Special Section João Carlos dos Santos Fagundes and Felix Alberto Farret. interruptions with failures and faults in the gate driver for the cereal dryer discharge system.

\section{THE CONVENTIONAL SYSTEM}

In Figure 1 it is presented the diagram for the commonly used pneumatic systems, called Conventional System [1], controlling a cereal drier discharge system used at BAGEL.

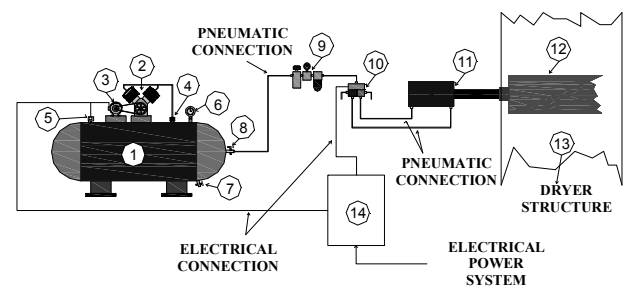

\begin{tabular}{cl}
\hline & TABLE OF SYSTEM COMPONENTS \\
\hline 1 & Air Reservoir \\
\hline 2 & Compressor \\
\hline 3 & Electrical motor \\
\hline 4 & Retention air valve \\
\hline 5 & Pressure sensor \\
\hline 6 & Compressor manometer \\
\hline 7 & Water drain valve \\
\hline 9 & Air output valve \\
\hline 10 & Lubricator of air filter pressure controller \\
\hline 11 & Pneumatic piston \\
\hline 12 & Group for the discharge gate \\
\hline 13 & Cereal dryer structure
\end{tabular}

Fig. 1. Lay-out of the Conventional System.

The analysis of the system in Figure 1 allows verifying that the Conventional System is made up basically by thirteen items, each one of them has several potential contribution points for fault generation in the system, that are able to interrupt the production flow, and that could be the main factors for process halting. Table I presents the possibilities of faults for the Conventional System.

TABLE I

Measure of contributions on halting the process for components of the Conventional System.

\begin{tabular}{cc}
\hline Group & $\begin{array}{c}\text { Contribution } \\
\text { (points) }\end{array}$ \\
\hline Pneumatic piston & 7 \\
Solenoid valve & 9 \\
Pressure regulator filter & 6 \\
Air compressing system & 17 \\
Mechanical gate starter & 4 \\
Air pressure switch & 4 \\
Electrical motor & 3 \\
Compressor draining & 2 \\
Air distribution system & 3 \\
\hline
\end{tabular}


The quality of compressed air is a factor that must be considered, if not handled conveniently, it can decrease the expected life time and performance of the equipment. In this case, care is necessary to drain water from the compressor reservoir; this must be done in variable intervals that are dependent on the relative air humidity. The operational procedure program is necessary to optimize this process, in order to have flux of cereal as large as possible. The control of the gate works enabled by a pressure switch, that is calibrated to switch on the compressor motor always when the pressure of the reservoir is below $100 \mathrm{Psi}$, and switches it off when the pressure is above 125 Psi. An end switch acts as a security system for the gate excursion in order to not allow it to exceed its mechanical limits. Two auxiliary relays operate the five way solenoid valve that controls the pneumatic piston in the gate opening and closure. Those relays are enabled by three time controlled relays; the first two relays are used to control the opening time and the time delay, the third relay controls the time the gate remains closed.

\section{THE PROPOSED LIM SYSTEM}

Due to high failure indexes in the so called Conventional System, the best alternative available is the LIM, due to its design characteristics and peculiarities. A well known LIM characteristic is that it doesn't show high peak starting current as an ordinary induction motor [4].

Figure 2 shows the details for the applied LIM.

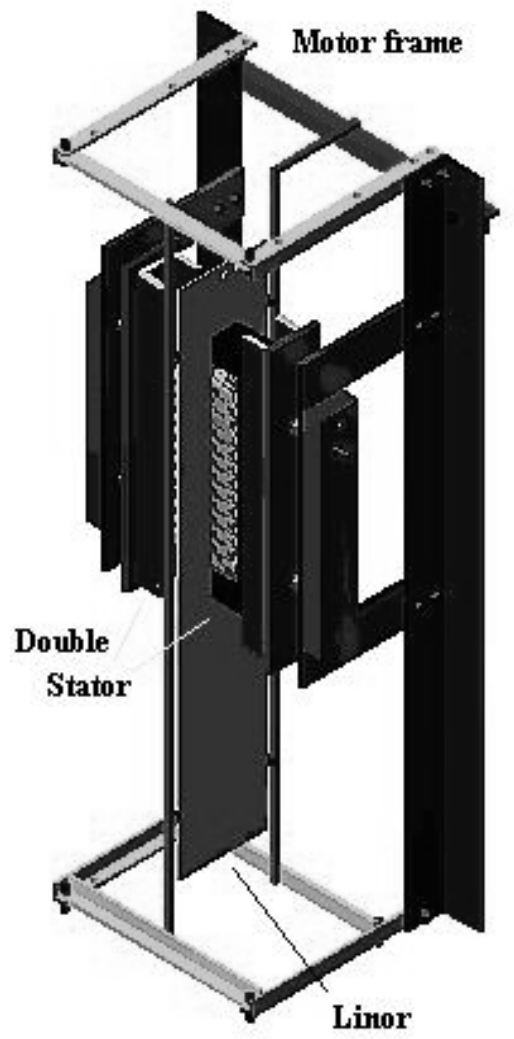

Fig. 2. Details of the LIM used in System 02.

Each winding bundle presents a four-pole three-phase configuration having a double layer in nine stator central slots and a single layer in six slots in both ends, being three in the input end and three in the output, as can be seen in Figure 3. Such configuration along with the stretching of the external teeth, that is made to ease the end effects, in this case unnecessary, due to the fact that is a low speed LIM.

TABLE II

\begin{tabular}{cc}
\hline \multicolumn{2}{c}{ LIM Physical dimensions } \\
\hline Pole number & 4 \\
Slot number & 15 \\
Polar step (mm) & 65 \\
Stator length (mm) & 400 \\
Stator bundle height (mm) & 113 \\
Stator bundle width (mm) & 45 \\
Teeth width at ends (mm) & 41 \\
Slot width (mm) & 10 \\
Teeth thickness (mm) & 12 \\
Slot depth (mm) & 50 \\
Stator sheet thickness (mm) & 0,35 \\
Sheet number per bundle & 130 \\
Linor material & Aluminum \\
Linor length (mm) & 1000 \\
Linor edge width (mm) & 160 \\
Linor thickness (mm) & 6 \\
\hline
\end{tabular}

The LIM used in this application depicted in Figure 2 was a prototype of a design with electrical parameters identical to the one used by Pontes [12][14], with specific physical dimensions given in Table II. A simulator has been built for the cereal dryer discharge gate driver, at the warehouse mechanical workshop, with the driver being the LIM, as shown in Figure 3. The aim of this work was to build an alternative system that presents high reliability index [9] and that is able to do the work showing some advantages to the conventional system. Such advantages are: the ability to reduce point of faults, to reduce maintenance service, adjustments are easier, and the focus of operator's work turns to inspection services, calibration and execution of other routines and procedures, aiming the final product quality and energy savings improvement.

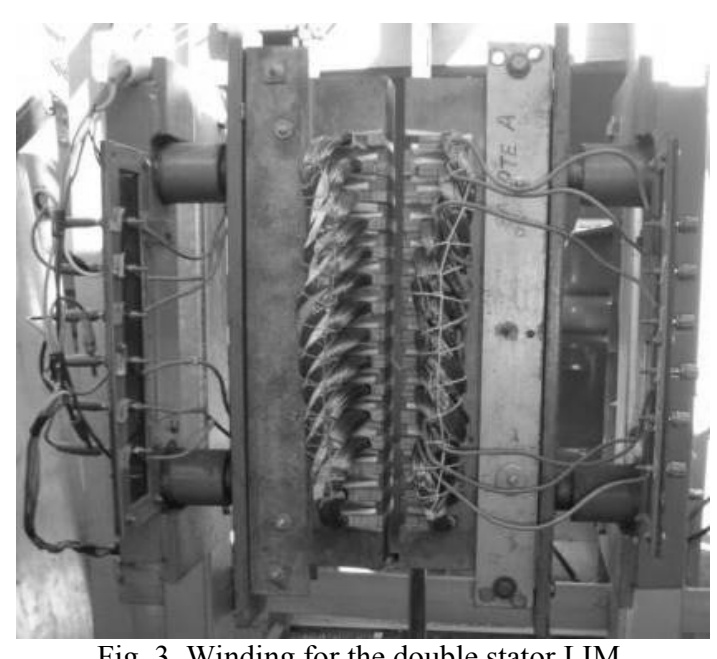

Fig. 3. Winding for the double stator LIM.

Winding was made with one coil per pole per phase, $\mathrm{q}=$ 1 , and each coil has 138 turns of a $n^{\circ} .19$ AWG wire. The polar step has $6.5 \mathrm{~cm}$. The winding in each bundle was a 
parallel delta $(\Delta)$ connection, making a double triangle system, as in Figure 4.

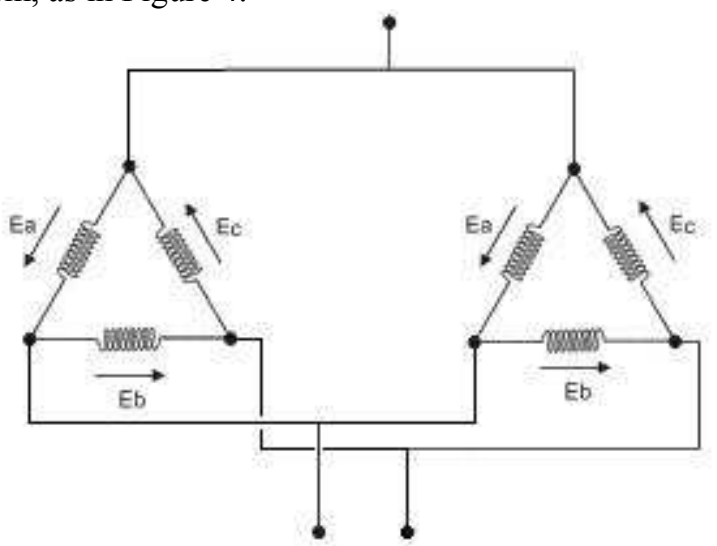

Fig. 4. Double delta for the primary bundle.

The control panel and the starter used in the Conventional System had a great deal of electrical simplification with the implementation of the same components [2][4][10].

A force multiplying lever was installed between the linor and the discharge gate set in the prototype, this was made to prevent trouble with the LIM design and to have the assurance that it would produce enough force, being able to perform the necessary tests during the simulation phase. The whole Simulator System is depicted in Figure 5.

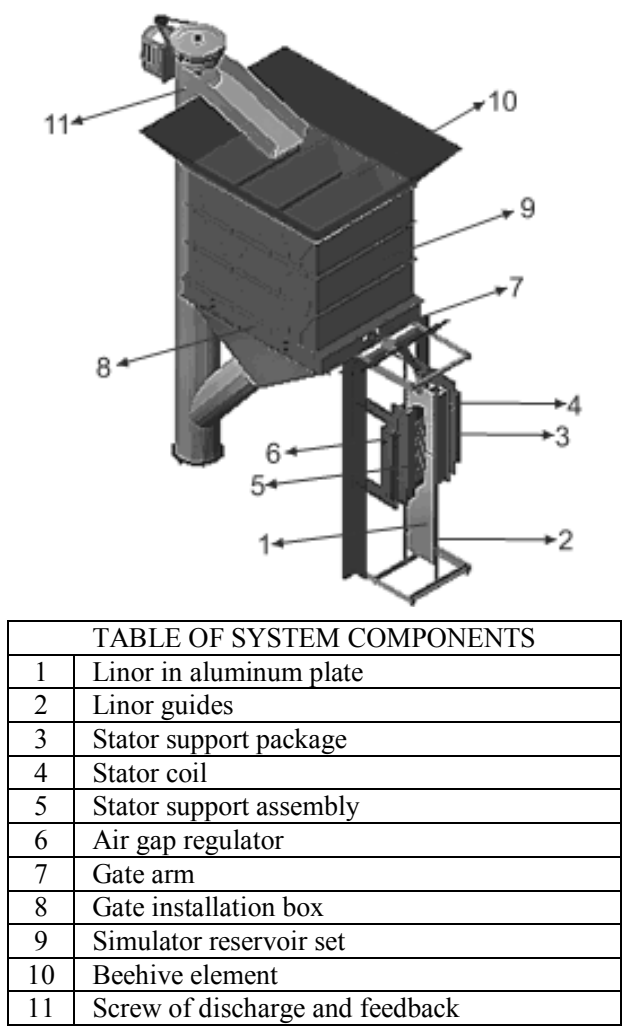

Fig. 5. Simulator details for the discharge gate in the LIM System.

\section{THE LIM FORCE CALCULATION}

Figure 6 shows the longitudinal cut for one of the two identical stator packages of the machine with slots and teeth.
Letters R, S, T, shows the three phase displacement of windings in the linear three-phase induction motor, and the signs indicate the opposite side of windings. The first and last three slots have only one winding per slot [13][14][15].

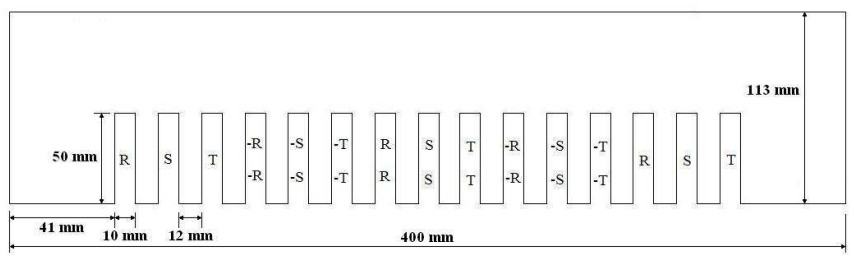

Fig. 6. Stator package for the linear induction motor.

An important aspect in the design of the LIM applied to the gate moving system is the evaluation of the force needed to open and close it. The force estimation can be done through the use of FEMM - Finite Element Methods on Magnetics [16]. In this case the complete knowledge of the design details and machine geometry should be known.

Electromagnetic potential surfaces can be seen through the simulation using FEMM, the current is balanced and nominal, is at its maximum in phase $\mathrm{R}$ and in phases $\mathrm{S}$ and $\mathrm{T}$ are displaced respectively by $120^{\circ}$ and $240^{\circ}$ from phase R.

Current density in the stator and linor can be observed in Figure 9 for the nominal condition producing force of 214.17 Newton (from Maxwell Stress Tensor), in the linor a substantial current exists to produce the necessary force.

The stress tensor [15] of an electromagnetic field in two directions $\alpha$ and $\beta$, that in SI units is given by:

$$
\sigma_{\alpha \beta}=\frac{1}{4 \pi} \varepsilon_{0} E_{\alpha} E_{\beta}+\frac{1}{\mu_{0}} B_{\alpha} B_{\beta}-\frac{1}{2}\left(\varepsilon_{0} E^{2}+\frac{1}{\mu_{0}} B^{2}\right) \delta_{\alpha \beta}
$$

$E$ is the electric field, $B$ is the magnetic field density, and $\delta$ is the Kronecker delta (a function of two variables $\mathrm{i}$ and $\mathrm{j}$ that equals 1 when $\mathrm{i}=\mathrm{j}$ and equals 0 otherwise), with $\mu_{0}$ and $\varepsilon_{0}$ being the permeability and permittivity of vacuum respectively.

The element $i j$ of the Maxwell stress tensor has units of momentum per unit of area and unit of time and gives the flux of momentum parallel to the $i^{\text {th }}$ axis crossing a surface normal to the $j^{\text {th }}$ axis per unit of time.

These units can also be seen as units of force per unit of area (pressure), and the ij element of the tensor can also be interpreted as the force parallel to the $i^{\text {th }}$ axis suffered by a surface normal to the $j^{\text {th }}$ axis per unit of area. Indeed, the diagonal elements give the pressure acting on a differential area element normal to the corresponding axis, obtained from the mapping of electromagnetic potential surfaces as in Figure 7.

Unlike forces due to the pressure of an ideal gas, an area element in the electromagnetic field also feels a force in a direction that is not normal to the element. This shear (rather than pressure) is given by the off-diagonal elements of the stress tensor. 


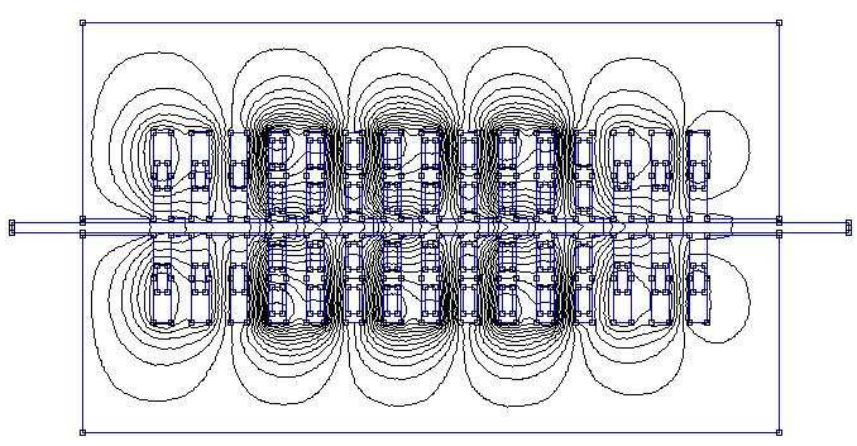

a)

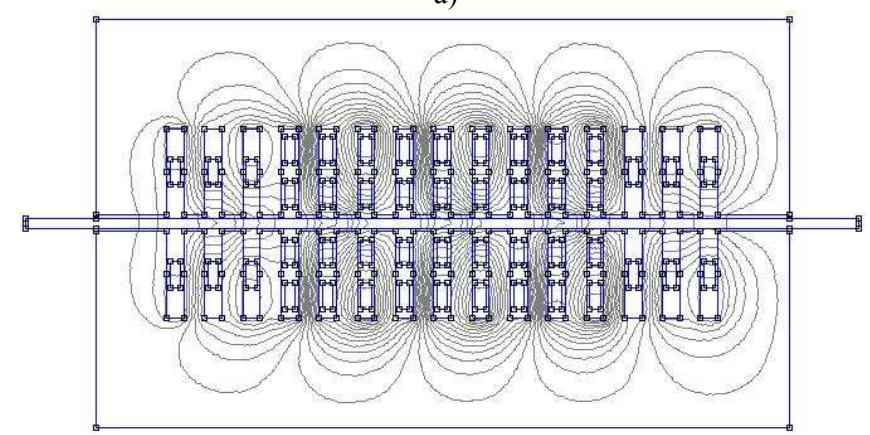

b)

Fig. 7. Electromagnetic potential surfaces a) active and b) reactive.

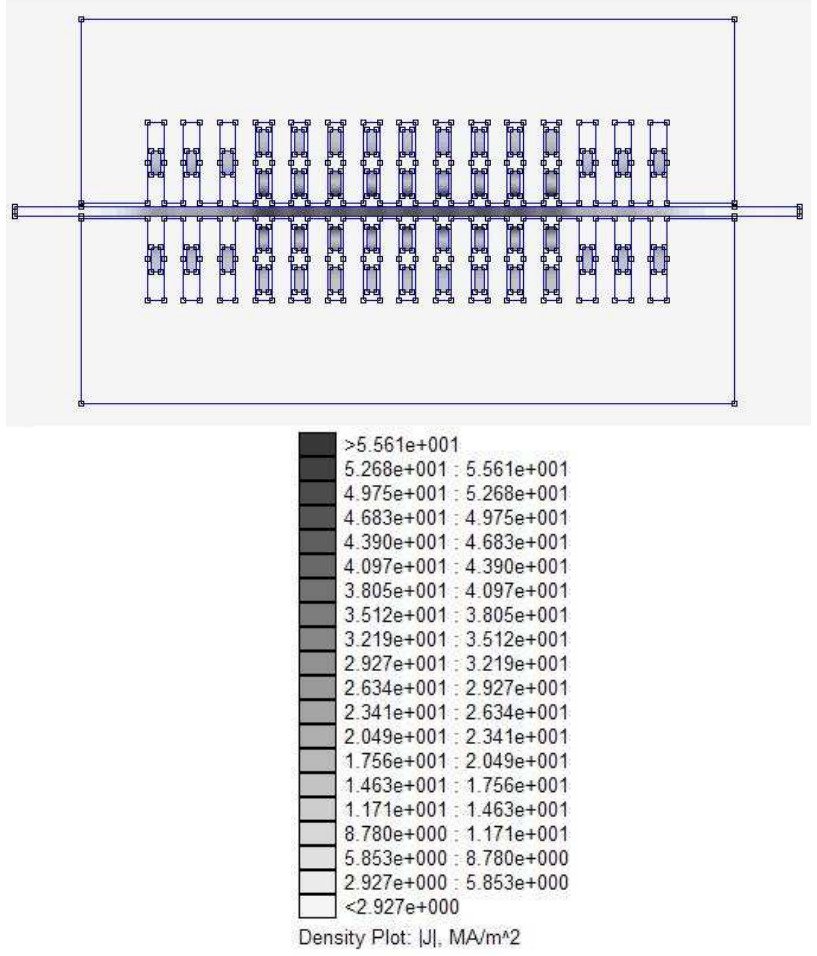

Fig. 8. Current density for nominal condition.

The magnetic flux density along the air gap is given by Figure 9.

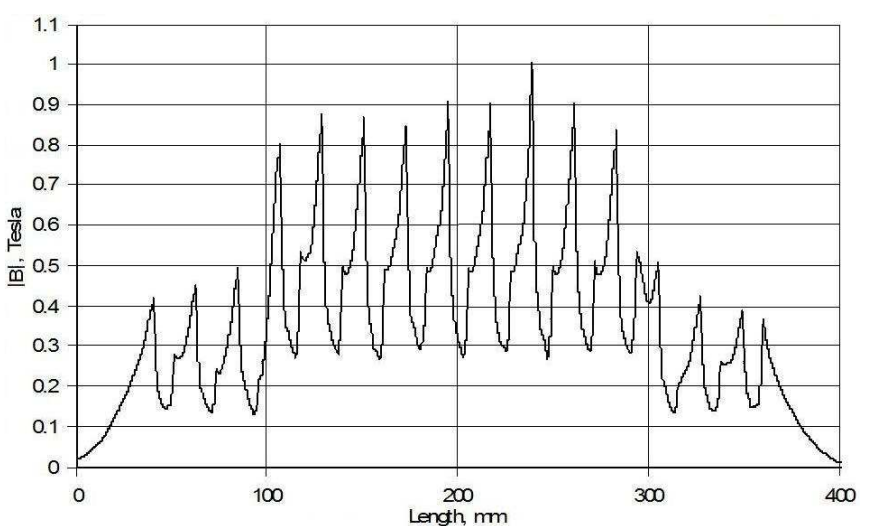

Fig. 9. Magnetic flux density along the air-ap.

Figure 10 shows the linor eddy current density $\left(\mathrm{J}_{\mathrm{e}}\right)$ in its absolute value, real and imaginary components respectively, to produce the necessary force to open the gate.

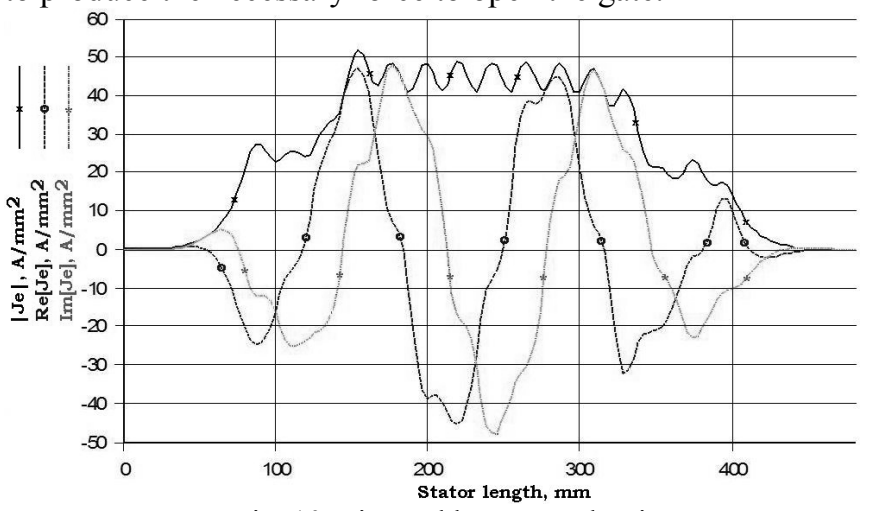

Fig. 10. Linor eddy current density.

\section{LIM SYSTEM OPERATIONAL OUTLOOK}

During the tests, the LIM was connected to the mains at a three-phase source $(220 \mathrm{~V}, 60 \mathrm{~Hz})$, and its terminals were connected in parallel delta, due to the fact that in its original connection, parallel star [12][14], the LIM didn't produce enough force to bring the prototype to motion. Since the proposal of the design is only for voltage and current short time interval pulse application, the LIM didn't show any major problem when in operation.

Measurements made in order to obtain the data for the study of the behavior of the LIM System has been carried out under the condition of no-load operation, due to the fact that the equipment operation didn't show much difference from nominal load to no-load condition. The only task of the LIM is to pull a lever where the weight of the grains is an immaterial aspect. Measurements of force were carried out taking into inconsideration its intensity in the linor and at the gate structure of the prototype.

Figure 11 shows the schematics when assembling instruments for the LIM operational tests in the prototype. 


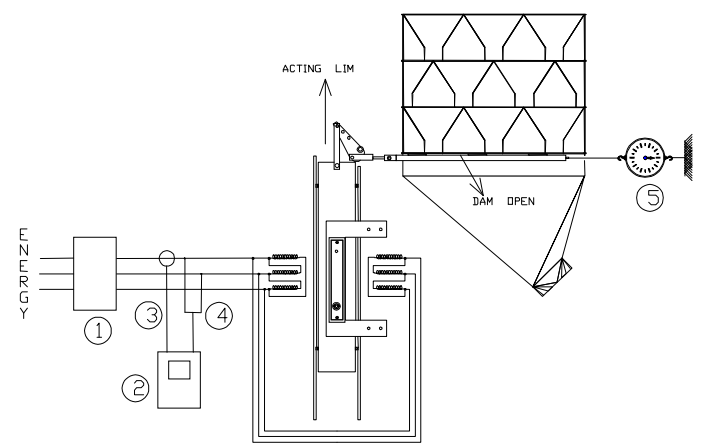

\begin{tabular}{cl}
\hline Legend & \multicolumn{1}{c}{ Description } \\
\hline 1 & Three phase network 220 V, 60Hz \\
2 & Scope model TEK HS720 \\
3 & current sensor \\
4 & voltage sensor \\
5 & Dynamometer scale $50 \mathrm{kgf}$ \\
\hline
\end{tabular}

Fig. 11. Schematic assembling for the prototype tests.

The method adopted to obtain active power data during the LIM prototype operation was with the two wattmeter method. The data extracted has been imported and displayed using the software WaveStar Version 1.2.2, and processed with a numerical integration program in $\mathrm{C}$ language, developed by the Electric Machines Laboratory at Universidade Federal de Uberlândia, MG, Brazil. For the complete operating cycle, waveforms for voltages at phases $\mathrm{A}-\mathrm{C}$ and $\mathrm{B}-\mathrm{C}$, and the current waveforms of phases $\mathrm{A}$ and $\mathrm{B}$ are presented.
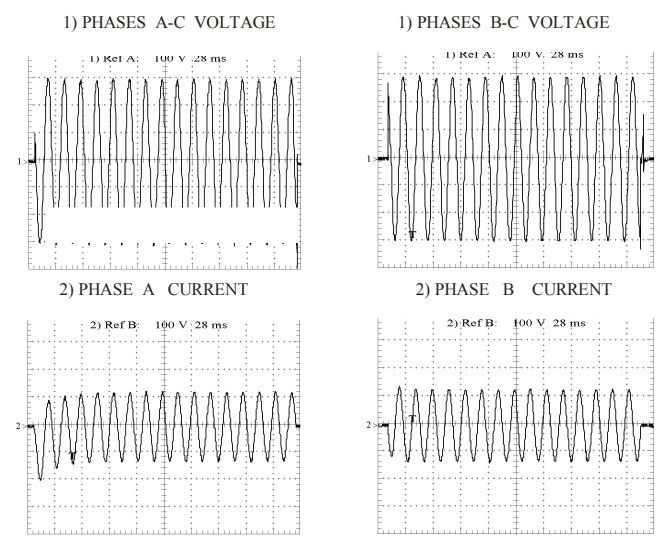

Fig. 12. Voltage and current forms for the complete cycle.

Figure 12 shows voltage and current waveforms obtained from LIM tests when driving the prototype, with the scale being compatible with values of voltage and current in Table $3,100 \mathrm{~V} /$ div for voltage and $10 \mathrm{~A} /$ div for currents.

From Figure 12 it can be verified that from [4]:

- The inexistence of important voltage fluctuation during the process of LIM starting and stopping.

- Starting current of the LIM, with normal acceleration slope shows little disturbance in the system.
- Voltage or current transients were not present during the LIM start and disconnection. LIMs do not show large current demand when starting.

- Stable voltages and currents for the LIM in steady state operation.

- Low power factor, due to the LIM design characteristics with high magnetization current.

The parallel delta connection provided a force to the LIM of $15 \mathrm{kgf}$, approximately $205 \mathrm{~N}$, considered well above the force of $56 \mathrm{~N}$ obtained in previous tests[12][14].

The gate of the prototype works controlling the flow of grains', from the drying tower to the inferior reception box.

The energy consumed for the LIM in each discharge cycle was considered an extremely low value, due to the fact that motor operates for around 0,25 seconds (16 voltage/current cycles) in each discharge cycle.

This system produces an intermittent draining of the product being stored in the reservoir. For each cycle the LIM opens the very fast, and is switched off, a defined amount of the stored product goes down to the inferior reception box, the gate is closed mechanically by a controlled spring, the stored product returns to the reservoir through helical transport thread. The whole cycle can be customized according to the time needed for the gate to remain opened.

The prototype was designed to perform in exactly the same fashion as the system in the field, with reduced flow scale, having a reservoir with the same duty cycle of the drying tower of an industrial dryer in the field.

The LIM system gate driver is enabled by an auxiliary contactor that makes possible the system to work in automatic or manually operated status. An end switch acts as a security and control device to assure that the gate does not exceed its mechanical excursion limits. The opening and closing of the gate is affected by contactor status (opened or closed) when energizing the LIM and supplying force to the gate. The time cycle for the LIM drive is controlled by only one time relay that in turn controls the operation of the locker.

Figure 13 shows a simplified drawing of the operating steps for the prototype.

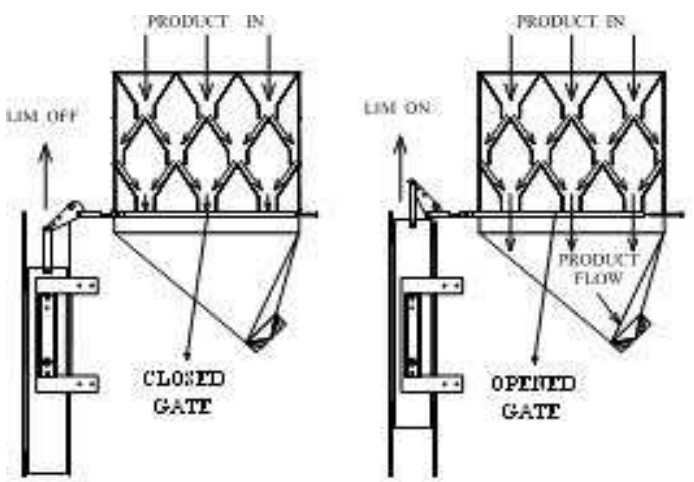

Fig. 13. Schematic for the working process of the prototype.

\section{RESULTS}

The achieved test results with the LIM operating the prototype are presented in Tables III and IV. 
TABLE. III

Obtained Test Results

\section{Measured Results}

Data acquisition: 02 wattmeter method

Data extraction: WaveStar software, Version 1.2.2

\begin{tabular}{ll}
\hline PARAMETERS & VALUES \\
\hline RMS Voltage phases C-A & $215.09 \mathrm{~V}$ \\
RMS Voltage phases B-C & $211.09 \mathrm{~V}$ \\
RMS Current phase A & $8.89 \mathrm{~A}$ \\
RMS Current phase B & $9.21 \mathrm{~A}$ \\
Active Power phases C-A & $1428.48 \mathrm{~W}$ \\
Active Power phases B-C & $320.07 \mathrm{~W}$ \\
Reactive Power phases C-A & $1271.19 \mathrm{VAR}$ \\
Reactive Power phases B-C & $1917.76 \mathrm{VAR}$ \\
Power Factor phases C-A & 0.747036 \\
Power Factor phases B-C & 0.164624 \\
Linor weight & $6 \mathrm{kgf}$ \\
Measure force in the linor & $15 \mathrm{kgf}$ \\
Measure force in the gate & $23 \mathrm{kgf}$ \\
\hline
\end{tabular}

TABLE IV

Obtained Final Results

\begin{tabular}{ll}
\hline PARAMETERS & VALUES \\
\hline Total Active Power & $1748.56 \mathrm{~W}$ \\
Total Reactive Power & $3188.96 \mathrm{VAR}$ \\
Power Factor & 0.480784885 \\
Applied nominal voltage & $220 \mathrm{~V}$ \\
Maximum force applied in the gate & $23 \mathrm{kgf}$ \\
Maximum operation time & 0.2 seconds \\
Consumed energy - each pulse & $0.097142106 \mathrm{Wh}$ \\
Operating temperature & $30^{\circ} \mathrm{C}$ \\
\hline
\end{tabular}

With the high incidence of faults, companies are forced to make large maintenance expenditure to keep the system working and not having the risk of high production losses. To reduce halting times due to equipment flaws, the industry need to have complete sets of spare parts and accessories for the whole system.

TABLE V

Halting and Loss Summary

\begin{tabular}{ll}
\hline $\begin{array}{l}\text { BAGEL }- \text { head office, } \\
\text { Storehouse } \mathrm{n}^{\mathrm{o}} 11\end{array}$ & $\begin{array}{l}\text { Product: Corn/Soy } \\
\text { Crop 2000/2003 }\end{array}$ \\
\hline $\begin{array}{l}\text { Summary hours of } \\
\text { process halting }\end{array}$ & $87: 10$ Hours:minutes \\
$\begin{array}{l}\text { Estimated production } \\
\text { loss }\end{array}$ & 3.700 Tons \\
Estimated reception loss & U\$ 30.000 \\
\hline
\end{tabular}

Due to the high probability of faults of the conventional system, it is necessary to have a highly skilled person to assist in such cases, so that the repair and fitting services are made with efficiency, resulting in increase of maintenance costs.

Table $\mathrm{V}$ was extracted from reports of process halting, referred to problems or faults in the dryer gate starter system that are part of the cereal storage system in years 2001, 2002 and 2003 respectively, when using the Conventional System.

In agreement with Table $\mathrm{V}$, the Conventional System presents number of hours with the process halted with expressive financial losses and losses of non-received products, a measure of the reliability of the system [8].

A comparative analysis for the two cases for power set up, consumption and cost of electrical energy is presented in Table VI.
Table VII presents comparative results of the feasibility study, in terms of power consumption for the operation of each prototype, with cost and monthly energy consumption for the two cases.

TABLE VI

\begin{tabular}{lcc}
\multicolumn{3}{c}{ Comparative Analysis } \\
\hline \multicolumn{1}{c}{ Parameters } & $\begin{array}{c}\text { Conventional } \\
\text { System }\end{array}$ & $\begin{array}{c}\text { LIM } \\
\text { System }\end{array}$ \\
\hline Motor (CV) & 0.5 & 2.4 \\
Utilization factor & 0.85 & 1 \\
N. ${ }^{\text {o operations per minute }}$ & 6 & 6 \\
N. ${ }^{\text {opperations per hour }}$ & 360 & 360 \\
$\begin{array}{l}\text { Operating time (hours) } \\
\text { Analyzed period in days }\end{array}$ & 24 & 0.3 \\
$\begin{array}{l}\text { Energy tariff (kWh peak } \\
\text { green tariff CELG) }\end{array}$ & 0.88266 & 30 \\
$\begin{array}{l}\text { Energy tariff (kWh pfs } \\
\text { green tariff CELG) }\end{array}$ & 0.10808 & 0.88266 \\
$\begin{array}{l}\text { Energy tariff (kW green } \\
\text { tariff CELG) }\end{array}$ & 10.34 & 0.10808 \\
$\begin{array}{l}\text { Consumption per } \\
\text { start (Wh) }\end{array}$ & 0.028 & 10.34 \\
$\begin{array}{l}\text { Monthly consumption } \\
\text { (kWh) }\end{array}$ & 228.42 & 0.245 \\
Monthly cost (U\$) & 54.54 & 63.50 \\
\hline
\end{tabular}

Tables VII and VIII shows cost values and consumption of energy. The LIM System has an installed power capacity 4.8 times larger; it presents cost and consumption of energy 3.6 times smaller, when compared with the Conventional System.

TABLE VII

Comparative Results

\begin{tabular}{cccc}
\hline \multicolumn{4}{c}{$\begin{array}{c}\text { Simulation } \\
\text { with Conventional System and LIM System }\end{array}$} \\
\hline Parameters & $\begin{array}{c}\text { Conventional } \\
\text { System }\end{array}$ & $\begin{array}{c}\text { LIM } \\
\text { System }\end{array}$ & Difference \\
$\begin{array}{c}\text { Motor power } \\
(\mathrm{CV})\end{array}$ & 0.5 & 2.4 & $-480 \%$ \\
$\begin{array}{c}\text { Consumption } \\
(\mathrm{kWh})\end{array}$ & 228.42 & 63.50 & $360 \%$ \\
$\begin{array}{c}\text { Energy cost } \\
(\mathrm{US})\end{array}$ & 21.87 & 6.07 & $360 \%$ \\
\hline
\end{tabular}

For the LIM System, likely causes for interruptions are reduced to six possibilities that comprehend faults related to:

- Electrical system source.

- Coils and physical characteristics of the LIM.

- Control system and gate starter.

- Gate mechanical structure.

- Fittings and operation of the discharge process system.

- Under dimensioned LIM.

The reasons to stop the implementation of the LIM System were reduced to six possibilities against more than forty eight when compared with the Conventional System.

Table VII shows a projection for the results, extracted from the analysis of productive action for the two systems, this study was made at the warehouse for cereal production from 2000 to 2003. 
TABLE VIII

Projection of Expected Results

\begin{tabular}{cccc}
\hline \multicolumn{4}{c}{$\begin{array}{c}\text { Simulation results for BAGEL in operation for the } 02 \\
\text { systems from 2000- } \mathbf{2 0 0 3}\end{array}$} \\
\hline Parameters & Conventional System & LIM & Difference \\
Stops (h) & 87.16 & 10.75 & $810 \%$ \\
Loss (Ton) & 3.700 & 700 & $528 \%$ \\
Loss (US\$) & 30.000 & 5.000 & $600 \%$ \\
\hline
\end{tabular}

The obtained values can be considered as a reference taking in consideration the same level of costs and energy consumption in more recent years.

\section{CONCLUSIONS}

A gate starter with a linear induction motor becomes a very attractive solution; it doesn't have as many mechanical parts as the Conventional System that can wear out easily, due to the fact that movement is created by induction and interaction of magnetic fields.

The control panel simplification for the LIM System, contributes for the improving in operating times related to adjustments, due to the fact that time adjusting for the desired operating cycle can be accomplished by the adjustment of only one time relay, while in the Conventional System the adjustments are made for at least 2 relays, what usually makes relay synchronization more difficult.

In the Conventional System the air compressor operating conditions has direct influence in the drying out quality of the product, due to the fact that the pneumatic piston only react correctly with the air pressure inside the range of tuning for the air pressure switch. For pressures below the range, the actuation speed for the pneumatic piston will be out of its optimal, affecting the performance of the gate starter, the result will be a non-uniform volume of product going through the gate.

In the LIM System the product flow is constant for each operation, and the volume depends only on the number of cycles. The duty cycle was not referenced here due to the fact of its strong seasonal dependence.

The amount of cereal after drying should contain a humidity content as uniform as possible in order to have a reliable storage [1][3][10][11].

Depending of the type and condition of operation a different approach is suggested for time and maintenance methods that will have large effect in the operational cost [8]. Simulation made using Finite Element Method was in agreement with results experienced in the field, the process make it easier to estimate in advance the force developed by the LIM [16].

This system is still working at the storage facility in Goiás State, and is working as predicted, with a very low failure rate and a great improvement on the company maintenance standards. It must be emphasized that this is a prototype and future systems must be improved based on this experience, concerning motor design and control system.

The results presented as: operational time earnings, productivity and energy efficiency makes the investment very attractive in the exchange of the Conventional Pneumatic System for the LIM System.
The cost of the artisanal linear induction motor to drive the gate is around half of the cost of the conventional system. With the LIM being assembled in a factory line the cost of the LIM is estimated to drop to $1 / 5$ of the conventional driving system.

\section{ACKNOWLEDGEMENTS}

We would like to acknowledge BAGEL - Armazéns Gerais Bom Jesus Ltda. and Universidade Federal de Uberlândia, School of Electrical Engineering for the support in the course of Mr. Tanimoto's work.

\section{REFERENCES}

[1] E. A. Weber, Agricultural Storage, Kepler Weber Industrial S.A., Porto Alegre, 1995, Brazil. (In Portuguese)

[2] E. R. Laithwaite, "Linear electric machines - a personal view", Proceedings of the IEEE, v. 63, n. 2, p. 250-290, 02-1975.

[3] D. Puzzi Seeds Supply and Storage, Campinas, Brazil: Instituto Campineiro de Ensino Agrícola, 1973. (In Portuguese)

[4] S. Yamamura, Theory of Linear Induction Motors, $2^{\text {nd }}$ ed. Tokyo: University of Tokyo Press, 1972.

[5] D. P. Guerrini, Contribution to the Study of Linear Induction Motors, São Carlos - SP. Escola de Engenharia de São Carlos - USP, Brazil, 1972. Doctoral thesis.(In Portuguese)

[6] O. J. Katano, Linear Induction Motors Applied to Electric Traction: Workbench and Prototype Analysis Driven by a Variable Frequency Inverter, São Carlos SP. School of Engineering - São Carlos - USP, Brazil, 1996. Master's degree dissertation. (In Portuguese)

[7] G. A. Simone, Three-phase Induction Machines: Theory and Exercises, São Paulo - Brazil: Editora Érica, 2000. (In Portuguese)

[8] T. Osada and Y. Takahashi, Total Productive Maintenance, São Paulo - Iman Institute $-2^{\text {nd }}$ Edition 2000.(In Portuguese)

[9] M. Sellitto, Equipment Reliability in the Strategic Formulation of Industrial Maintenance, available in http://inf.unisinos.br/ sellitto/manconfsist.pdf, accessed in 15-01-2006.(In Portuguese)

[10]L. C. Silva, Seed Drying, available in http://www.agais.com/ag0405_secagem.pdf, accessed in 15-10-2005.(In Portuguese)

[11]L. C. Silva, Seeds: Conservation methods, available in http://www.agais.com/ag0805_metodos_conservacao_gr aos.pdf, accessed in 15-10-2005. (In Portuguese)

[12] E. B. dos Santos, L. Martins Neto, J. R. Camacho and R. S. T. Pontes, "A Linear Induction Motor Parameter Determination Method", COBEP99 - The 5th Brazilian Power Electronics Conference - Foz do Iguaçu - Brazil September, 19-23, 1999.

[13]E. B. dos Santos, L. Martins Neto and J. R. Camacho, "Linear Induction Motor Parameter Determination on Force Development Applications"; Proceedings of the IEEE - PES - Winter Meeting 2000 - Singapore, January, 23-27, 2000. 
[14] R. S. T. Pontes, L. Martins Neto, J. R. Camacho, R. V. R. Silva, "A Linear Induction Motor Applied to a Guillotine", MagLev 2000 - The 16th International Conference on Magnetically Levitated Systems and Linear Drives - Rio de Janeiro - Brazil, June, 7-10, 2000.

[15]R. Becker, Electromagnetic Fields and Interactions, Dover Publications Inc., 1964.

[16]FEMM - Finite Element Methods on Magnetics, available in http://tinyurl.com/2p8oac.

\section{BIOGRAPHIES}

Sussumu Caliento Tanimoto was born in Pontal, SP, Brazil on January, $15^{\text {th }}, 1956$. He received his Electrical Engineering degree with emphasis in Electro-technical Engineering at UFU Universidade Federal de Uberlândia, MG, Brazil, in 1980. He got his MSc in Electrical Engineering at UFU with emphasis in Electrical Engineering for Industrial Systems in 2006. Currently he is a maintenance supervisor at BAGEL-ARMAZÉNS GERAIS BOM JESUS LTDA, Bom Jesus, GO, Brazil.
Décio Bispo was born in São Vicente, SP, Brazil on November 18th, 1952. He got his Electrical Engineering BSc degree from UFU in 1979, and his MSc and Doctoral degrees in Automation and Electrical Machines from UNICAMP respectively in 1985 and 2000. He is a Senior Lecturer at Universidade Federal de Uberlândia, MG, Brazil were he works since August 1979. His areas of interest are Electrical Machines and Industrial Applications

José Roberto Camacho (M'1993, SM'2006) was born in Taquaritinga, SP, Brazil on November $3^{\text {rd }}, 1954$. His Bsc in Electrical and Electronic Engineering was obtained in December 1978 at Universidade de Uberlândia, Federal College of Electrical Engineering, Uberlândia, MG, Brazil. He got his MSc degree at UFSC - Universidade Federal de Santa Catarina, Brazil, in 1987, and $\mathrm{PhD}$ degree in the Electrical and Electronic Engineering Department at Canterbury University, Christchurch, New Zealand, in August 1993. He is a Senior Lecturer at Universidade Federal de Uberlândia where he works since February 1979. His areas of interest are Electricity for Rural Applications and Alternative Energy. Dr. Camacho is Senior Member of the IEEE. 